\title{
POSITIVE INTERACTIONS AS A DRIVING FORCE IN EVOLUTION AND COMMUNITY STRUCTURE THROUGH TIME
}

\author{
WALKER, Sally E., Dept. of Geology, University of Georgia, Athens, GA 30602 , \\ U.S. A.
}

Positive, or facilitative, ecological interactions can contribute to cohesiveness of a community. Previously, negative interactions (i.e., competition and predation) have been suggest to contribute to community structure, but it now appears that mutualistic interactions, whether obligate or facultative, may be the driving force for the structure and cohesiveness of many ecological communities. Mutualisms, considered by many to indicate positive interactions, can actually vary along an ecological, and in many cases, an evolutionary continuum, from beneficial to antagonistic interactions. For example, symbionts may become pathogenic over time and parasites may or may not be pathogenic (can be symbiotic) when viewed over the life cycle of the organism or over evolutionary time scales. Thus, parasitism, mutualism and symbiosis are just variations on a theme of associations if viewed from this eco-evolutionary perspective which differ in few ways from the leitmotiv of Anton de Bary in 1878.

While modern ecological theory is just struggling with this newly revised theory of mutualism as a continuum of interactions, fossil interpretations are still rather mired in the static interpretation of mutualism: that mutualisms are rare in the fossil record and thus unimportant, and that they are "unstable" in evolutionary time. Quite the contrary is true. Whole systems of fossil organisms are related by mutualistic interactions. They are geographically widespread and have enjoyed a long, if you wish, "stable" evolutionary history when viewed from the fossil record. Many of these mutualistic associations have crossed major extinction boundaries: From the Mesozoic we have coral-zooxanthellae symbioses, foraminiferal-algal symbioses and hermit crab-bryozoan associations and from the Paleozoic, fossils of mycorrhizal fungi, lichens and presumed sipunculid-bryozoan symbioses. Some of these associations are species-specific, but by and large, these associations are facultative. In all cases, they are produced by positive interactions that have contributed to largescale community structure (e.g., corals, fungi: life on land) or small scale communities (hermit crab biocoenoses) or produced major carbonate sediments (e.g., corals and forams) that directly or indirectly influenced the community structure of other organisms that live in or degrade these sediments. Mutualistic interactions are also involved in the evolutionary development of major groups of organisms (protozoan phylogenies; the eukaryotic line) and evolutionary novelties. In addition to the escalation hypothesis, I would add cooperation; rather than just an arms race, a "handshake" as well. A more fuller understanding of community evolution will emerge once positive interactions are evaluated. 